\title{
KTH Celebrates 175th Anniversary with Symposium on Nanostructured Materials
}

The Royal Institute of Technology $(\mathrm{KTH})$ in Stockholm, Sweden, is celebrating its 175th anniversary in 2002. As part of the commemoration of its founding, the Department of Materials Science and Engineering arranged a two-day symposium on April 11-12, 2002, on the subject of nanostructured materials, focusing on contributions by women in materials sciences. The organizers, K.V. Rao, chair of the department; Malin Selleby, program manager of the department's Center for Computational Thermodynamics; Lyubov M. Belova, postdoctoral fellow in the department; and Börje Johansson, visiting from Uppsala University, Sweden, invited 30 materials scientists in the field-mostly women-from Europe and the United States. The speakers provided a broad overview of current research in the field.

Talks ranged from nanotube spectroscopy (Mildred S. Dresselhaus, Massachusetts Institute of Technology, USA) to molecular-dynamics simulation (Helena Van Swygenhoven, Paul Scherrer Institute, Switzerland) to magnetic nanoparticles (Sara A. Majetich, Carnegie Mellon University, USA). Presentations included implications of nanomaterials research in biotechnology (Viola Vogel, University of Washington, USA) and the environment (Inger Odnevall Wallinder, KTH) and interdisciplinary connections such as the role of theoretical and computational chemistry in materials science (Kersti Hermansson, Uppsala University).

In addition to the technical presentations, the organizers invited a group of high school seniors from the Engelskaskolan Söder (the English School South) to attend an afternoon of talks. The scientists discussed opportunities in the materials area in industry, academia, and government institutions, as well as provided presentations including "puzzles and fun with nano" (Merrilea J. Mayo, U.S. National Academies) and "fractals around us"

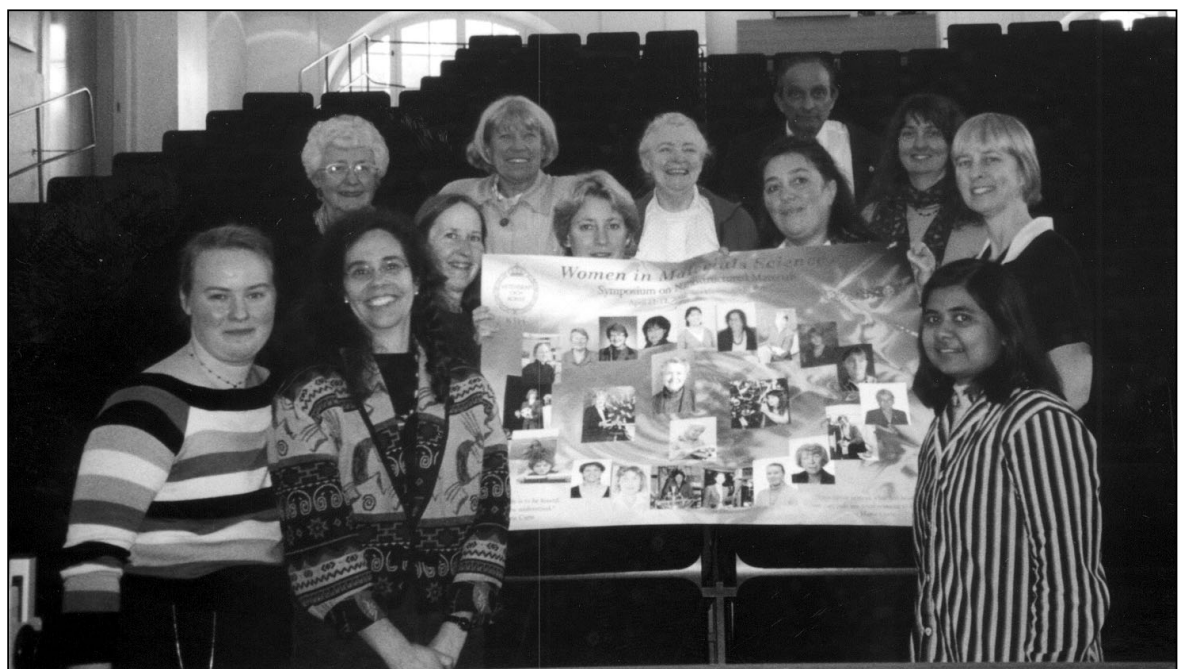

The Department of Materials Science and Engineering celebrated the 175th anniversary of the Royal Institute of Technology (KTH) in Stockholm, Sweden, with a symposium on Nanostructured Materials: Focusing on Contributions by Women in Materials Sciences. Two of the co-organizers are shown holding the conference poster with 10 of the 30 invited speakers: (front, left to right): co-organizer Lyubov M. Belova (KTH), Viola Vogel (University of Washington, USA), and Amita Gupta (KTH); (holding the poster, left to right): Sara A. Majetich (Carnegie Mellon University, USA), Caroline A. Ross (Massachusetts Institute of Technology, USA), Elena Obraztsova (Russian Academy of Sciences), and Merrilea J. Mayo (U.S. National Academies); (back row, left to right): Julia Weertman (Northwestern University, USA), Marija Kosec (University of Ljubljana, Slovenia); Mildred S. Dresselhaus (Massachusetts Institute of Technology, USA), co-organizer K.V. Rao (KTH), and Kris A. Bertness (National Institute of Standards and Technology, USA).

(Gillian Gehring, University of Sheffield, U.K.). This session was designed to interest the young people in a career in materials science. Three of the students have since arranged to spend six weeks in the summer as young researchers on nanostructured materials in one of the KTH laboratories.

As most of the presenters were women, the organizers took the opportunity to host a panel discussion on women in science. Among the issues addressed was a review of the International Conference on Women in Physics held in Paris March
7-9 of this year. Most telling was the group of attendees to the KTH conference itself: With a few notable exceptions, the audience was largely female, leaving much up to speculation as to why so few men attended.

For the women, the conference demonstrated their achievements in producing a body of research of breadth and excellence.

JULIA WEERTMAN

With contributions from K.V. Rao, Co-organizer

\section{Over 6,000 Proceedings Papers Now Online For "Members Only" \\ MRS members have free access to all published proceedings papers from MRS Meetings since the 2000 MRS Spring Meeting. Plus free online access to MRS Bulletin and the MRS Membership Directory.}

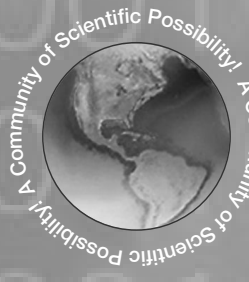

Go to www.mrs.org and click on "Members Only"

Not a member?

Go to www.mrs.org and click on "Join MRS" to become a member today! 